AMERICAN

JOURNAL OF BOTANY

VOL. VIII $\quad$ MAY, I92I $\quad$ No. 5

\title{
ISOACHLYA, A NEW GENUS OF THE SAPROLEGNIACEAE ${ }^{1}$
}

\author{
C. H. Kauffman
}

(Received for publication December 29, 1920)

Isoachlya Kauffman gen. nov. Hyphae rather stout or slender. Zoosporangia formed from their tips, oval, pyriform, ventricose-clavate, the later ones (secondary) arising either by cymose or pseudo-cymose arrangement as in Achlya, or by internal proliferation as in Saprolegnia, both modes occuring earlier or later in the development of one and the same species, or frequently on the same main hypha. Zoospores diplanetic, as in Saprolegnia, escaping and swarming separately, and after encystment swarming the second time before the formation of a germ tube. Oogonia terminal or torulose, occasionally intercalary. Oospores with centric contents, the spores filling the oogonium incompletely. Antheridia present or few to none.

The genus is characterized and distinguished, in the main, by the presence of the cymose or Achlya mode of formation of secondary sporangia, coupled with diplanetic zoospores. The following species naturally fall within its boundaries:

I. Isoachlya toruloides Kauffman and Coker sp. nov.

2. Isoachlya paradoxa (Coker) comb. nov. Achlya paradoxa Coker. Mycologia 6:285. 1914 .

3. Isoachlya monilifera (de Bary) comb. nov. Saprolegnia monilifera de Bary. Bot. Zeit. I6: 629. 1888 .

Isoachlya toruloides Kauffman and Coker sp. nov.

Hyphae rather slender and short, $18-20 \mu$ in diameter, later ones frequently smaller, straight and scarcely branched. Zoosporangia oval, pyriform, clavate-pyriform, more rarely elongated-pyriform, with a more or less distinct papilla; secondary sporangia, during the early and vigorous develơment, all cymosely arranged by successive basipetal formation, sometimes from the walls of earlier ones, later secondary sporangial initials appearing by internal proliferation as in Saprolegnia; zoospores diplanetic, capable of escaping and swarming separately, encysting after coming to

${ }^{1}$ After this paper was in the hands of the editor, a letter from Prof. W. G. Coker, of Chapel Hill, N. C., indicated that he was describing the same new genus and species. An exchange of data confirmed this supposition and hence it was agreed to publish them under joint authorship. The descriptions and figures to be given by Professor Coker have been examined by me, and I believe they apply to the same fungus.

[The Journal for April (8: 179-230) was issued April 30, 1921.] 
rest, and after their second escape germinating by a germ tube. Oogonia globular, short-pyriform or pyriform-globular, with a more or less short hyphal base, produced at the ends of main hyphae in basipetal series, or mixed with the sporangia in a sporangial series, up to 6 in a series (as far as observed), persisting in series until or after maturity of oospores; their walls firm, soon becoming pale brown, with more or less scattered, distinct, small pits, sometimes numerous. Oospores centric, $\mathrm{I}-3$ in an oogonium, rarely 4 or 6 , at maturity with a thick wall and a granular central sphere separated from the wall by a layer of uniform thickness; the spores measure 16-22 $\mu$. Antheridia and antheridial branches none or very rare.

Two collections: in shallow water over peat-like organic remains, shore of First Sister Lake, Ann Arbor, Michigan, and in a pool of sphagnum near by. Taken November 23. Cultivated on the house-fly, Musca domestica, from single zoospores.

This species has for its nearest relative "Saprolegnia monilifera de Bary," from which it differs in that its oogonia are persistent in the series in which they are formed until after the maturity of the oospores and the breaking down of the supporting hyphae. The oogonial pits, although scattered, are distinct, while in "Saprolegnia monilifera" they are said to be few or none. In de Bary's species the most general mode of proliferation of the secondary sporangia is by the method found in the species of Saprolegnia, while in the present species they are formed for the most part by the cymose method, and for a considerable time during my observations of fly cultures I did not see the other arrangement, not indeed until the cultures became comparatively old. The appearance of the sporangia-bearing hyphae, and the mode of proliferation of successive secondary sporangia, can be seen by referring to figure $4, a-c$ (Plate XIII). This is the regular process on the house-fly in 30-40 cc. of water, varying only in minor details. The oospores in the oogonia are also less numerous than appears to be the case in de Bary's species, but the character may vary somewhat in this group, even on the same substratum-although within limits-by reason of slight differences in the vigor of the mycelium as a result of a larger immediate food supply. In "Saprolegnia monilifera" the oogonia are said to be produced in great abundance, and sporangial formation is reported to be almost completely ended when the oogonia begin to form. In Isoachlya toruloides, on the other hand, sporangia and oogonia are of ten formed at the same time, from the time oogonia begin to form until the age of the culture and the toxic condition of the water begin to produce an effect and chlamydospores appear instead.

The zoosporangia develop in the usual manner, and spore formation as seen in a living culture indicated nothing unusual. When the zoospores are ready to escape, the papilla at the apex of the sporangium is dissolved and they swim out at a fairly rapid rate and slowly scatter to a short distance before rounding up. I have followed this procedure in normal cases. A typical case is as follows. The culture had been kept in a cool glass- 
surrounded enclosure, to which a partially opened window gave access to outside temperature during the winter months. The temperature usually fluctuated between $0^{\circ}$ and $10^{\circ} \mathrm{C}$. The culture was four days old and had developed at these lower temperatures, and when examined on February I4 had been in a temperature slightly below $8^{\circ} \mathrm{C}$. for at least twenty-four hours. Zoosporangia were very abundant, all primary and apical, many mature, several empty, and with motile zoospores present in the upper layer of water. These primary zoosporangia were pyriform to ventricosepyriform in shape. In the course of half an hour or so, during examination in the warmer temperature of the laboratory, many mature sporangia opened, and in a relatively short time the water was alive with zoospores. There was every indication that they were already ciliated in the sporangium. As they lined up more or less within the sporangium, after the latter had opened, they assumed an oblong shape, obscurely curved on one side and with rounded ends, and not at all pyriform as frequently described for Saprolegnias; but, as was seen later during their evolutions immediately after escaping, they had an unequal diameter in their short axes, i.e., they were slightly flattened.

A zoospore was uninterruptedly followed from its emergence, the instant it had become free of the opening at the tip of the zoosporangium. It was seen to turn over and over on its long axis, at the same time slowly getting away from the neighborhood of the others, which were all turning somersaults in the same curious way. Meanwhile the elongated, sub-oblong or slightly sub-reniform shape was retained. This continued for about twenty minutes, during which time every movement could be followed. Neither this spore nor the others, as far as observed, ever exhibited the darting or rapidly swimming habit of zoospores of the species of Saprolegnia. At the end of this period other manifestations began to appear. The spore-always turning-began in a more or less spasmodic manner to hump itself somewhat on its convex side, then to straighten out again, and after several such performances to show signs of a shortening process. Gradually during the last five minutes, by a twisting and shrugging process, it became much shorter and one end became contracted, so that a short pyriform shape, or an oval form with a papilla, resulted; this was soon changed, however, to a more and more globular form until finally a perfect sphere resulted. No let-up of the turning which it had exhibited over its longer axis could be detected up to this time, and even for perhaps twenty seconds after it appeared to have become perfectly rounded it still continued to revolve. Then very quickly all motion ceased, and the spore assumed its first resting condition.

Observations following this at intervals during the next few days showed that the spores, after rounding up, gradually sink to the bottom of the dish except when, sometimes in great numbers, they are caught in the mesh of mycelium surrounding the fly. After several days, the bottom of the 
dish is literally covered by a thin layer of such spores and an equal number of empty spore-capsules. In some cases the contents of the spores were seen emerging, but so slow did this process appear to be that none were ever observed to swim away in the second swarming stage. On the other hand, a great many spores whose structure indicated that they were the end product of the first swarming stage were seen germinating by germ tubes, which eventually became slightly branched by short outgrowths. This is not uncommon in other species of the family. By transferring these empty capsules along with germinated and ungerminated spores to a slide and adding chlor-zinc iodide, no immediate reaction occurred, although a mature oogonium in the mount took a deep stain. On adding to this a rather strong iodine solution (in potassium iodide), the characteristic color for fungus cellulose appeared. The walls of the empty capsules, of the spores, and of the germinating threads, were definitely stained. The spores, during the period after the first swarming stage until they germinated, became more and more vacuolate. The scanty food supply demands that the germination tubes draw upon the protoplasmic content of the spore, and eventually doubtless they will perish, thread and spore. Although several weeks had elapsed since the first spores had germinated, no sign of sporangial formation at the end of the germination filaments was ever noted, although this occurs frequently in other species when food supply is lacking in the solution, and is perhaps to be found as a specific characteristic of certain species under other conditions.

We may now turn to the reactions of this species under certain definite conditions. The description so far is that of its "normal" behavior on a sterile house-fly in sterile conductivity water of high purity. If grown on fruit-flies (Drosophila), the rapidity with which the stages of its development follow one another is quite marked. The sporangia appear many hours earlier after exposure of the flies to the zoospores, and sexual reproduction is several days ahead of the time for cultures on the house-fly. The food is more rapidly diffused and exhausted.

In a solution of haemoglobin 0.05 percent $+\mathrm{KNO}_{3}$ o.I percent, four days old, at the temperature mentioned before, the culture is found to have developed very abundant oogonial initials, arranged in torulose series as shown in figure Io, $a, b$ (Plate XIV), and in some cases the terminal oogonium has already formed oospheres. The latter tend to be more numerous in each oogonium than is the case in fly cultures. At this same time the house-fly was densely covered with short, straight hyphae, nearly all bearing sporangia, mature or maturing or with sporangial initials. After ten days in this solution the earlier series had produced oospheres and some oospores, but those developed later showed signs of abnormality and disintegration.

In a solution (always with conductivity water) of haemoglobin 0.05 percent, in this case with an addition of 0.12 percent levulose, a culture 
four days old, under the same temperature conditions, showed the same general abundance of oogonial initials, but in this case the oogonial swellings occurred at the ends of stalks in pairs, in series of two, or with one on an adjacent short lateral stalk. After ten days the greater number of these had developed further, so that the terminal one possessed oospheres or oospores while the basal ones were initials and in many cases showed signs of never being able to complete their destiny. Later observations showed this surmise to have been correct, the apical ones maturing further, the contents of the basal ones breaking down. (See fig. I r, $a-c$.)

In a o.I percent solution of leucin, under the same conditions, after four days only scattered and quite young oogonial initials were seen. After ten days they were abundant, and a large proportion contained oospheres. But in this case the globular oogonia were borne singly at the ends of long supporting hyphae, not more than $\mathrm{I}$ to 2 percent being in series of two. (See fig. 12, $a-c$.)

In all the cultures mentioned, no antheridia were ever observed. The pits of the oogonial wall were always rather far apart, not large, and in leucin unusually distinct. The torulose habit of the oogonia is reduced as we go down this list of cultures. The presence or absence of some substance in the synthetic solutions is doubtless responsible for the inability of the development of the later oogonia to run its usual course. Although no combinations with mineral salts were extensively tried with the haemoglobin and leucin solutions, work on other species has shown that there is no reason to suppose that the disintegrating effects of the haemoglobin and leucin could not be offset by the addition of proper amounts of certain salts, the oospheres thus being induced to complete their development to maturity. It will be noted that the period of time necessary for the appearance of the reproductive organs is not strictly an inherent quality within the species, but depends, within limits, on certain other influences. The older investigations laid great stress on the exact period of time which any process, in the life history of a species, took to complete itself. In view of many indications in this and other groups of plants, this attitude needs to be much changed before we can lay a sound foundation for plant morphology. In records of cultures of the Saprolegniaceae it is still frequent to see flies, wasps, white of egg, this, that, and the other substratum mentioned without further details, as if the organism were assumed to act alike on all.

"Saprolegnia monilifera de Bary" has, so far as I know, been observed and studied only by de Bary himself. He found it only in one lake, near the Black Forest, Germany, from which he obtained it repeatedly, but was never able to get it from any other of his collections made through many years. De Bary considered its nearest relative to be Saprolegnia torulosa of the "ferax" group; but he placed it in a separate section which he called the "monilifer" group. Its anomalous position was thus clearly recognized by de Bary, and since this was the only case known to him in which both 
types of secondary sporangia were present, de Bary's native conservatism naturally induced him to attach it to one of the older genera.

An addition to the species which have this anomalous character of two modes in the formation of secondary sporangia during a sexual reproduction, was made recently by Coker (l.c.). He referred his species to the genus Achlya, as " $A$. paradoxa," and felt disinclined to erect for it a new genus, on the ground that the anomalous character in question establishes merely a "narrow point of contact" and is not unlike similar intermediate species in Puccinia and Uromyces. While this is clearly the case, limitations to genera cannot go on indefinitely encircling more and more exceptions, else one of the main reasons for the building up of the scientific classification of plants becomes abortive. Furthermore, in a group of such a small number of species as the Saprolegniaceae, the case becomes very different, by lack of balance, from the case in the genera of rusts cited. It seems to me, then, that by the erection of the genus Isoachlya, a double objective is attained: the limitations of the old genera remain clearly defined, and the new genus takes a most natural place within the family of the Saprolegniaceae.

BOTANICAL LaBoRatory, University of Michigan

\section{LITERATURE}

The student is referred to the extensive bibliography by Klebs for the older papers, and to Weston for more recent work.

Klebs, G. Zur Physiologie der Fortpflanzung einiger Pilze. II. Saprolegnia mixia. Jahrb. Wiss. Bot. 33: 513-593. 1899.

Weston, W. H. Observations on an Achlya lacking sexual seproduction. Amer. Jour. Bot. 4: 354-366. 1917 :

\section{EXPLANATION OF PLATES}

The higher magnification was obtained with Bausch and Lomb $15 \times$ ocular and $3 \mathrm{~mm}$. objective, the lower with $15 \times$ ocular and $8 \mathrm{~mm}$. objective. All are equally reduced. Figures $1-9$ are from cultures on sterilized house-flies, in 25-40 cc. conductivity water, from single zoospores; all cultures were free from other organisms.

Plate XIII

FIG. I. Sporangial initials of Isoachlya toruloiles on head of a fly, two days after inoculation.

FIG. 2, a. Young hypha before swelling. $b-h$. Stages in the development and maturity of zoosporangia.

FIG. 3, $a-f$. Escaping zoospores and form changes in the process of assuming the first resting stage. $a$. During first twenty minutes. $b$-e. Gradual changes during next thirty minutes. $f$. Completely rounded and at rest. No cilia are shown, since full data were not obtained, but they are doubtless two in number and lateral.

FIG. 4, $a-c$. "Achlya" type of formation of secondary sporangia, after nine days.

FIG. 5, a-e. Different types of oogonia, showing the normal variation in number of oospores as the fungus occurs on flies. After nine days.

FIG. 6. "Saprolegnia" type of formation of secondary sporangia. The proliferation in the two empty sporangia would become the third in the series. After thirteen days. 


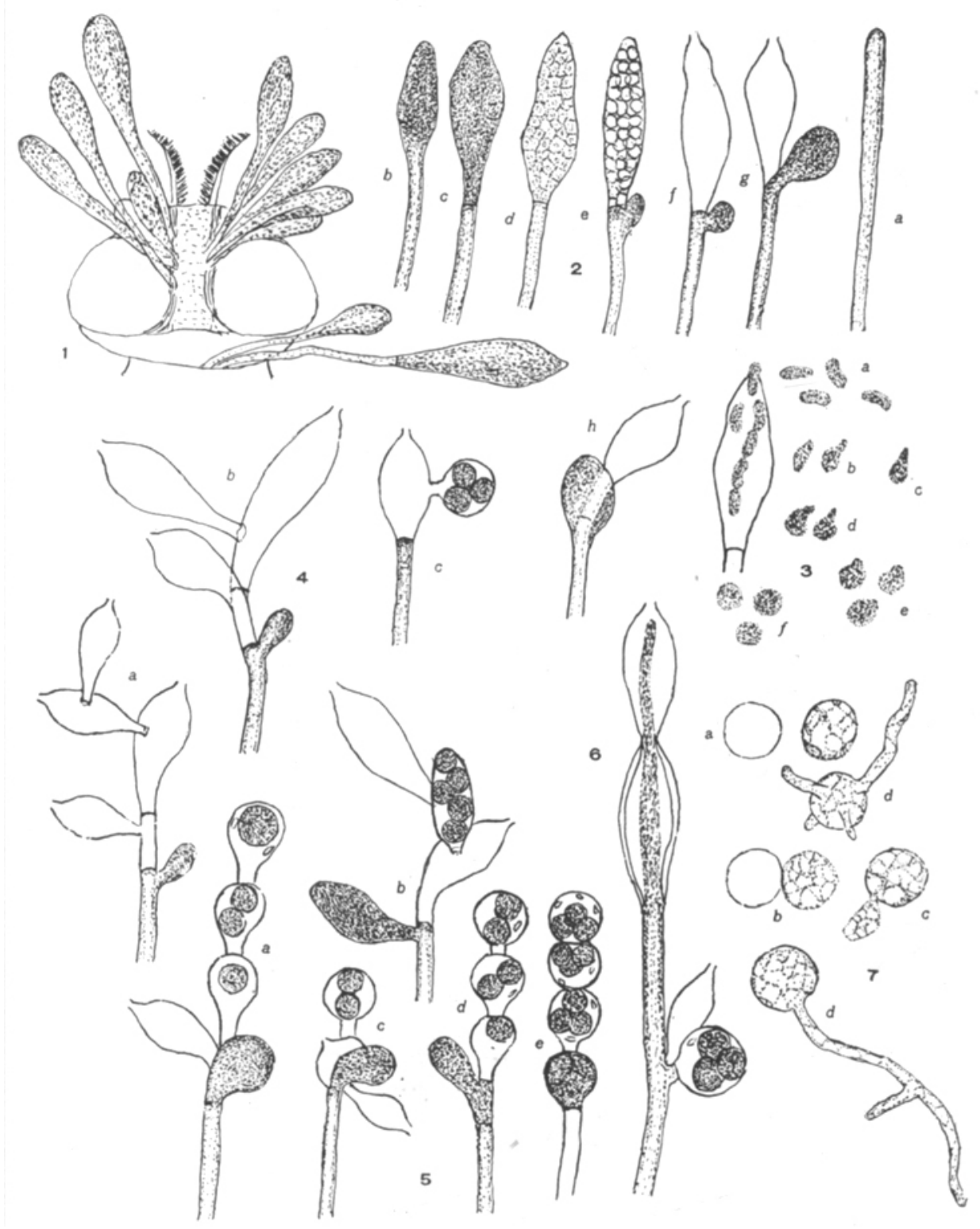

KAUFFMAN: ISOACHYLA. 

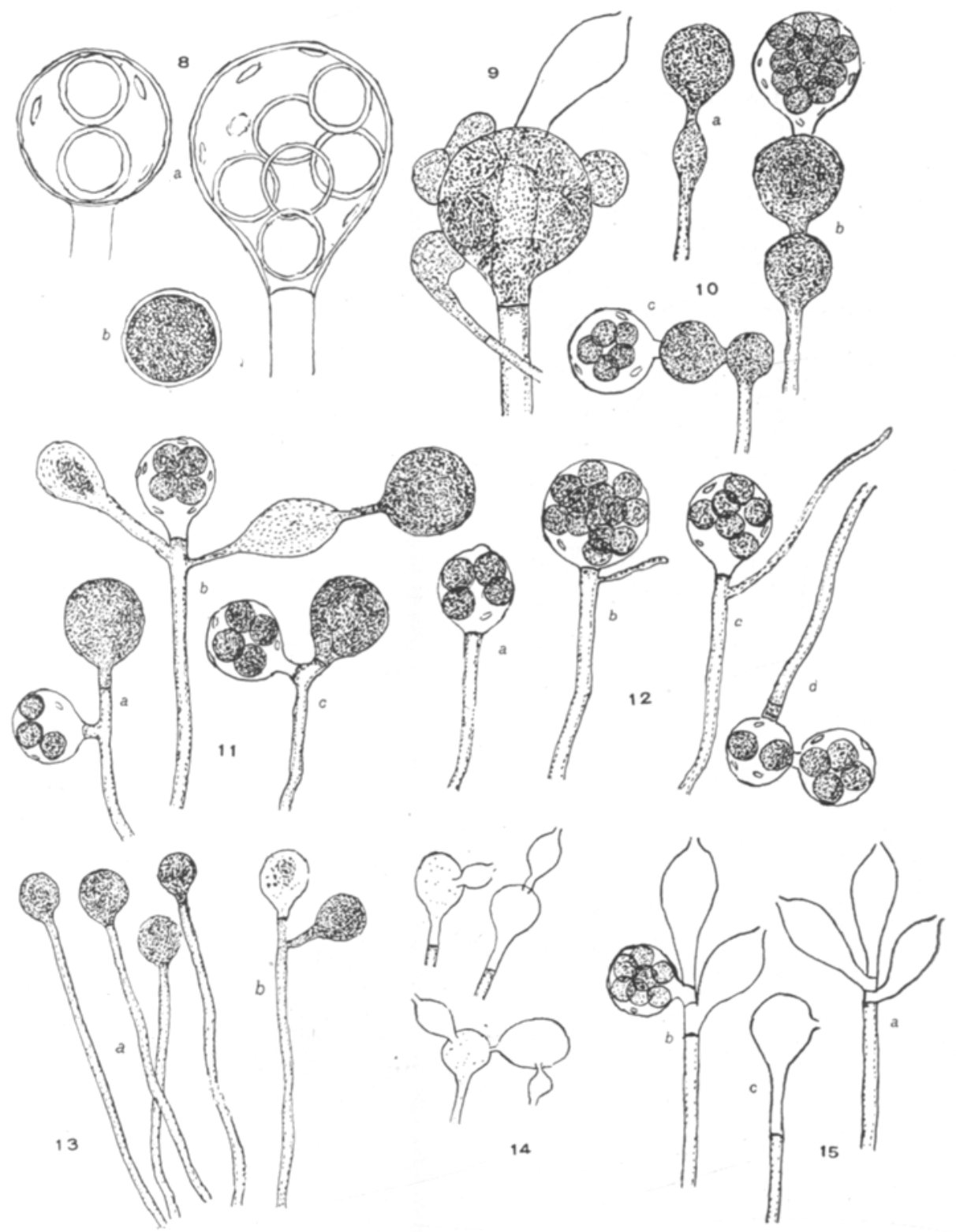

KAUFFMAN: ISOACHYLA. 
Fig. 7. After the end of the first swarming stage. a. Empty spore walls. $b$. Escaped but quiescent, naked cells. $c$. Act of escaping of cell. $d$. Germination by one or more germ tubes, the second "swarming" being omitted.

\section{Plate XIV}

FIg. 8, a. Two examples of oogonia with mature oospores. $b$. A single mature oospore, much enlarged. After thirteen days.

Fig. 9. One of few occurrences of an oogonium with antheridia. Antheridia nearly mature; oogonium young. After 8 days.

FIG. 10, $a-c$. Oogonial arrangement in solution of haemoglobin $0.05 \%+\mathrm{KNO}_{3} 0.1 \%$. Note the larger number of oospores per oogonium. After four days.

FIG. II, a-c. Oogonial arrangement in solution of haemoglobin $0.05 \%+$ levulose $0.12 \%$. After twelve days. $90 \%$ of oogonia occur in pairs.

FIG. I2, $a-c$. Oogonia arranged singly at ends of long stalks, frequently with vegetative outgrowths below the oogonium, and oospores rather numerous. From culture in $0.1 \%$ leucin. $d$. In $0.02 \%$ leucin. In this weaker solution the. inhibitive effect of leucin for the torulose arrangement is reduced. Both after ten days.

FIG. 13, $a$. In $0.02 \%$ peptone, after five days. $b$. After ten days. The oogonia are unable to mature in this solution.

FIG. I4. From peptone cultures in condition shown by figure 13, washed in distilled water for an hour, then transferred to distilled water. The initials become zoosporangia and the zoospores have escaped. After twenty-four hours.

FIG. 15. From culture in $0.02 \%$ peptone. $a$. Note regular arrangement of the basal walls of sporangia. $b$. Neat illustration of the doctrine of homology of different organs of reproduction. One of few oogonia which produced oospheres in this solution. $c$. An oogonial initial becoming a zoosporangium with scarcely any external morphological change. 